\title{
De movimentos nascem flores: análise ergológica de um processo de compostagem
}

\author{
Flowers from movements: an ergological anaylis of a composting process
}

\author{
Las flores nacen de los movimientos: un análisis ergológico de un proceso de \\ compostaje
}

\author{
Hugo Gama Peres dos Santos ${ }^{i}$ \\ Samara Leal Nascimento ${ }^{\text {ii }}$ \\ Talita Nascimento T. Coelho ${ }^{\text {iii }}$ \\ Simone Oliveira ${ }^{\text {iv }}$
}

\begin{abstract}
Resumo: Este artigo buscou analisar a relação trabalho, saúde e subjetividade no processo de compostagem de uma instituição pública no Rio de Janeiro, a partir da perspectiva ergológica. Para isso, a observação prévia dos trabalhadores em situação de trabalho foi seguida por entrevistas. Os resultados dessa incursão foram devolvidos aos trabalhadores através de Encontros sobre o Trabalho (EST), que contemplaram o debate sobre as normas antecedentes do trabalho e as renormatizações. Os trabalhadores participaram dos EST trazendo mais exemplos das microgestões e decisões cotidianas, das dificuldades para enfrentamento do trabalho real, manifestando uma verdadeira dinâmica mobilizadora do coletivo. Foi identificada uma gestão caracterizada pelo baixo controle sobre a produção que permite o exercício da autonomia desses trabalhadores, não só em relação à gestão das pausas e horários de descanso, mas também em relação à decisão pelo modo de realização das tarefas, possibilitando o desenvolvimento de diferentes modos operatórios, através do uso da comunicação e cooperação. Foi possível identificar também que as trocas linguageiras no e sobre o trabalho fortalecem a produção do coletivo ampliando suas possibilidades de ação.
\end{abstract}

\begin{abstract}
This article sought to analyze the relationship between work, health and subjectivity in the composting process of a public institution in Rio de Janeiro, from an ergological perspective. For this, the previous observation of workers in a work situation was followed by interviews. The results of this incursion were returned to the workers through Meetings about the work, which contemplated the debate on the antecedent norms of work and the renormatizations. The workers participated in the Meetings, bringing more examples of micromanagement and daily decisions, of the difficulties in facing real work, showing a real mobilizing dynamic of the collective. It was identified a management characterized by the low control over the production that allows the exercise of the autonomy of these workers, not only in relation to the management of breaks and rest times, but also in relation to the decision by the way of accomplishing the tasks, allowing the development of different operating modes, through the use of communication and cooperation. It was also possible to identify that language exchanges in and about work strengthen the collective's production, expanding its possibilities of action.
\end{abstract}

Resumen: Este artículo buscaba analizar la relación entre trabajo, salud y subjetividad em el proceso de compostaje de una institución pública em Río de Janeiro, desde una perspectiva ergológica. Para esto, la observación previa de los trabajadores en una situación laboral fue seguida por entrevistas. Los resultados de esta incursión fueron devueltos a los trabajadores através de Encuentros sobre el Trabajo, que contemplo el debate sobre las normas antecedentes del trabajo y las renormatizaciones. Los trabajadores participaron en los Encuentros, trayendo más ejemplos de microgestión y decisiones diarias, de las dificultades para enfrentar el trabajo real, mostrando una dinámica de movilización real del colectivo. Se identificó una gestión caracterizada por el bajo control sobre la producción que permite el ejercicio de la autonomía de estos trabajadores, no solo em relación com la gestión de descansos y tiempos de descanso, sino también em relación com la decisión por la forma de 
cumplir las tareas, permitiendo el desarrollo de diferentes modos de funcionamiento, mediante el uso de la comunicación y la cooperación. También fue posible identificar que los intercambios de idiomas en y sobre el trabajo fortalecen la producción colectiva, ampliando sus posibilidades de acción.

Palavras-chave: Atividade; Enco;tros sobre o Trabalho; Ergologia; Ergonomia; Trabalho.

Keywords: Activity; Meetings about the work; Ergology; Ergonomics; Work.

Palabras claves: Actividad; Encuentros sobre el trabajo; Ergología; Ergonomia; Trabajo.

\section{INTRODUÇÃO}

Ao longo dos séculos o trabalho passou por grandes transformações, atingindo fortemente a materialidade, a subjetividade e a forma de ser da classe trabalhadora (ANTUNES, 2009). O trabalho segue então como elemento estruturante da vida, mesmo com suas muitas transformações. Não sendo possível falar em um fim do trabalho como alguns autores, chegaram a supor (RIFKIN, 1995). No entanto, observa-se a mudança da relação do homem com o trabalho em uma lógica capitalista cada vez mais perversa, justamente de desvalorização do trabalho (SCHWARTZ; DURRIVE, 2010). Como categoria central na vida das pessoas, o trabalho se constitui em operador de saúde, ou fonte de adoecimento, a depender das possibilidades de ação dos trabalhadores (OSÓRIO-SILVA; RAMMINGER, 2014).

No contexto neoliberal atual, o individualismo e a competitividade são incentivados e os coletivos são minados, e o trabalho como um processo de determinação social da saúde assume um papel fundamental na configuração das condições de saúde da população. $O$ trabalho flexível, parcelado e precarizado aumenta as demandas e pressões sobre os trabalhadores. Pensar a relação saúde-doença a partir da atividade dos trabalhadores, de como se mobilizam e fazem essa gestão, é fundamental. A partir do ponto de vista da atividade, fortalecer o coletivo ampliando o seu poder de agir de maneira a favorecer a construção de ambientes de trabalho mais favoráveis a saúde pode ser revelador.

O presente artigo surge de reflexões sobre os resultados de uma análise ergonômica realizada no processo de trabalho de uma área de compostagem para fins de avaliação final da disciplina "Análise Ergonômica do Trabalho", ministrada pela Escola Nacional de Saúde Pública Sergio Arouca (ENSP/FIOCRUZ) em julho de 2019. Embora o foco da disciplina tenha sido a realização de uma análise ergonômica, sentiu-se a necessidade de ampliar o olhar a partir da perspectiva ergológica trazendo o debate de normas e valores presentes na atividade. Sendo o trabalho permeado por acontecimentos inesperados com discrepâncias entre o prescrito e o real, trabalhar é preencher essas lacunas, e é importante que se construam espaços de diálogo e reflexão para que as renormatizações presentes, os debates 
de normas, essa dimensão gestionária do trabalho circule ressignificando o trabalho e se transforme em patrimônio.

Dessa forma, deu-se continuidade ao projeto inicial incorporando outras ferramentas teóricas e metodológicas. No caso dos trabalhadores da compostagem, é importante pensar no comprometimento do quadro de saúde tendo em vista a grande exigência física do trabalho e promover reflexões que colaborem para a construção de sentido no trabalho.

\section{TrabalHo, SAÚDE E SUBJETIVIDADE}

A organização do trabalho atual exige novas competências dos trabalhadores que se tornam mais complexas e fluidas nas relações de trabalho, produtoras de contradições. Apesar do aumento dos trabalhos intelectualizados, observa-se o quanto o corpo é afetado e solicitado em qualquer tipo de trabalho. Valoriza-se a autonomia no trabalho ao passo que a padronização dos procedimentos é fortemente requisitada. A comunicação é considerada uma competência chave enquanto os coletivos de trabalho são minados (SCHWARTZ; DURRIVE, 2010). Assim, também são muitas as contradições expressas na relação trabalhosaúde.

O conceito de saúde é situado por Caponi (1997) como uma questão filosófica, debatida desde a época clássica por autores como Descartes, Leibniz, Diderot e Kant. Georges Canguilhem segue a indicação de Descartes de que há uma parte do corpo humano que é acessível somente a seu titular para construir sua argumentação de saúde como conceito filosófico e vulgar (comum), pois todos os seres humanos compartilham a experiência da dor e do sofrimento e também vivem silenciosamente a saúde. Assim, os seres humanos estão totalmente implicados quando se fala em saúde. A saúde não é um saber científico, mas um saber do sentido, base para abordar o cuidado em saúde (CAPONI, 1997).

Portanto, o conceito de saúde é complexo e fluido, no sentido que envolve diversos fatores e olhares, ao associar o campo físico, biológico, psíquico e social. Analisar as questões de saúde apenas por uma ótica e, principalmente, sem considerar a singularidade de cada sujeito, pode comprometer o julgamento. Para o modelo biomédico, a saúde poderia ser entendida como ausência de doença ou como equilíbrio biológico. Enquanto que para a OMS, seria um estado de bem-estar físico, mental e social, conceito criticado por apresentar uma condição inatingível para os seres humanos (BRITO, 2017).

Nesse sentido, para Canguilhem (2009), a saúde é uma luta e o equilíbrio total só encontramos na morte. Para ele, a saúde não pode ser reduzida à capacidade adaptativa, mas deve ser pensada como essa capacidade normativa de instituir normas diferentes em 
condições diferentes. Os seres humanos são normativos e uma vida contrariada, impedida, é o que levaria ao adoecimento.

Segundo Canguilhem (2009), normativo é o que institui as normas, e a vida é atividade normativa e polaridade dinâmica. A doença é apreendida como um valor negativo e o ser humano luta contra aquilo que surge como perigo à manutenção da vida. Nesse sentido, a vida comporta um estado de saúde e um estado de doença, não existindo limiar entre eles. É como se o organismo fosse um pêndulo que sempre caminha entre esses polos, criando normas para se ajustar a determinados meios, inclusive no trabalho. Normatividade é a possibilidade de transgredir as normas vigentes e moldar novas. Para o autor, saúde como atividade normativa é a capacidade de mobilizar os recursos internos para superar as infidelidades do meio.

Exemplo dessa polaridade dinâmica é que um sujeito pode passar de um estado em que ele consegue abusar da saúde, em que a saúde é invisibilizada quando está tudo bem, para um estado em que, para aprópria preservação do organismo, este cai doente para se dar o tempo de recuperação (CAPONI, 1997). Nesse sentido, é interessante o conceito de Dejours (1986, p.11) para quem a saúde é uma sucessão de compromissos com a realidade; "a saúde é a liberdade de dar a esse corpo a possibilidade de repousar, é a possibilidade de lhe dar de comer quando ele tem fome, de fazê-lo dormir quando ele tem sono, de fornecerlhe açúcar quando baixa a glicemia. É, portanto, a liberdade de adaptação”.

A doença seria então uma restrição dessa liberdade, restrição da normatividade. É quando o sujeito tem reduzidas suas possibilidades de ajustamento ao meio, sua amplitude de criação de novas normas. Assim, Canguilhem (2009) reforça que a experiência do ser vivo inclui a doença e ninguém permanece em plena saúde. É essa restrição da liberdade, causadora de adoecimento, que pode ser observada na vida da maior parte dos trabalhadores hoje em um contexto neoliberal.

Schwartz afirma que "o trabalho nunca é pura execução” (SCHWARTZ; DURRIVE, 2010, p. 189). Mesmo o trabalho mais mecânico comporta subjetividade e inventividade, na medida em que sempre há criação, produção de algo novo. O trabalho não é uma "simples submissão a procedimentos" (Ibidem, p. 189), porque isto seria invivível. Cada um procura nele o equilíbrio entre o uso de si requisitado e consentido (SCHWARTZ; DURRIVE, 2010).

Esse ajuste para Schwartz é sempre tentativa individual e coletiva de reinventar maneiras de fazer, maneiras de viver as contradições (DURRIVE, 2011). A atividade de trabalho compreende aquilo que deve ser rearranjado, inventado pelos trabalhadores, é o elemento central organizador e estruturante da situação de trabalho. Assim, toda atividade 
de trabalho é sempre, por um lado, descritível como um protocolo experimental e, por outro, experiência e encontro. Assim, todo trabalho tem um duplo aspecto, aquilo que nele é previsível, mas também aquilo que escapa a qualquer definição, um modo de ser/fazer que se constitui no ato do ser humano com seu trabalho.

Isso faz com que a atividade não seja antecipável, pois o trabalho nunca é feito de antemão. O risco está sempre presente, o que coloca o sujeito em uma dramática do uso de si, na medida em que precisará fazer inúmeras escolhas (microgestões) a partir de seus valores e experiências e assumir suas consequências (SCHWARTZ; DURRIVE, 2010).

O que remete ao conceito da dupla infidelidade do meio, inspirado pela ótica canguilheniana (SCHWARTZ; DURRIVE, 2010). O meio é sempre infiel, nunca se repete, o que faz com o que o protagonista do trabalho precise fazer uso de si, de suas capacidades, recursos e escolhas para gerir essa infidelidade e o vazio de normas, já que como dito anteriormente as prescrições são insuficientes. E como esse uso de si por si é sempre uma maneira pessoal de agir, que ressingulariza o meio com sua história e valores, isso traz uma variabilidade suplementar ao meio que se torna mais infiel.

E tudo isto acontece através do corpo-si (SCHWARTZ; DURRIVE, 2010), que não se refere somente à pessoa física, mas a este corpo que é um centro de arbitragens na escolha de valores. Este é um conceito complexo, propositalmente, para fugir de simplificações. Compreende o fato que o sujeito tem um corpo que é ao mesmo tempo físico, biológico, psíquico, histórico, social, cultural, enfim, singular. Estas dimensões não podem ser separadas, estão interrelacionadas, imbricadas, e é esta entidade complexa que é o árbitro da atividade. É ele quem decide no debate de normas em cada situação singular, qual caminho seguir, que ação tomar, que comportamento manifestar, quais palavras proferir.

A maneira como se senta, como se escreve, como se aperta um parafuso, como se inclina o corpo quando o interesse do sujeito é despertado, como se passa para um assunto trivial para aliviar a pressão, as infinitas escolhas diárias, tudo isso é o corpo-si em ação. Assim, atrás de toda complexidade e singularidade, "o sujeito escapa sempre de ser objetivado" (SCHWARTZ; DURRIVE, 2010, p. 197).

O histórico de decisões arbitradas por esse corpo-si gera um patrimônio, que também é herança dos mais velhos, e a confiança entre o coletivo é fundamental para essa transmissão de conhecimento. Por isso, a terceirização, a precarização das relações de trabalho, a fragilidade das relações traz consequências graves para o desenvolvimento do trabalho e para saúde das pessoas. Pode-se perceber que a atividade é enigmática! Não se dá a conhecer facilmente. A atividade nunca será apreendida por completo, sempre haverá uma dimensão 
que escapa da análise, uma característica que não será observada, elementos que não serão conhecidos, interferências que não vão ser notadas nem mesmo pelo trabalhador, protagonista do trabalho. Conforme Schwartz (2011, p. 59), "a atividade humana pode ser então definida como lugar de debate de normas. Sendo assim, o agir humano é um emaranhado de renormatizações". O debate de normas é uma forma de confrontar o enigma do trabalho, produzindo renormatizações a todo o momento na atividade.

É claro que "aceitar a sua complexidade e a impossibilidade de resolver todos os enigmas da atividade não implica se recusar à tarefa árdua do pesquisador de buscar o máximo de compreensão possível” (AZEREDO SILVA; MUNIZ, 2017, p. 56). Mas é preciso compreender que "nunca daremos conta de tudo que atravessa a atividade" (Ibidem, p. 42). Conforme aos mesmos autores (p. 41), "a atividade industriosa humana é uma noção sobre a qual nunca será dita a última palavra”, será um conceito sempre inacabado.

Dessa forma, segundo Ferreira (2000), a atividade não pode nem ser considerada um objeto de pesquisa, porque não é estática, já que toda atividade é singular, dinâmica, e como se refere ao que é especificamente humano no trabalho, este sujeito implica uma infinidade de relações com o meio, consigo e com os outros, pois ninguém trabalha sozinho.

O conceito de "entidades coletivas relativamente pertinentes" (SCHWARTZ; DURRIVE, 2010, p. 193), que é mais amplo que falar em equipes, traz essa perspectiva dos vínculos e relações que atravessam a atividade. Segundo Durrive, o trabalho é ao mesmo tempo uma realidade profundamente coletiva e individual:

\footnotetext{
Os outros de parte a parte atravessam a atividade, sua própria atividade. Eles estão presentes em você, estão presentes na intimidade de suas escolhas e, consequentemente, há uma dialética muito profunda que não é constitutiva de você, mas que o trabalha profundamente, neste modo pelo qual, escolhendo esse ou aquele procedimento ou modalidade de ação, você escolherá, de uma certa maneira, a relação com os outros ou o mundo no qual você quer viver (SCHWARTZ; DURRIVE, 2010, p. 192).
}

A atividade de trabalho, então, para ser uma atividade operadora de saúde precisa permitir que os trabalhadores tenham certa área de manobra para criar novas normas, para atender aos pedidos do corpo e para dar o devido direcionamento para sua energia vital. No entanto, é importante destacar que toda atividade é contrariada, considerando que atividade não é só o que se faz, mas tudo o que não se faz, que se sonha, suas frustrações etc.

A partir dessa perspectiva, também a análise do trabalho dos profissionais da compostagem, levando em conta o real da atividade, será fundamental para entender como estes se relacionam com o seu trabalho, com seus colegas, como lidam com as limitações e frustrações possíveis e como produzem saúde ou não a partir de sua atividade e de seu 
coletivo de trabalho. É no trabalho que acontece a construção coletiva de recursos para ação. E é com base nesta perspectiva que se pretende com este projeto contribuir para que os trabalhadores da compostagem construam juntos novos olhares sobre si e novos recursos para enfrentar as limitações e as muitas infidelidades do meio em que atuam, resgatando a potência do coletivo na produção de saúde.

\section{Metodologia}

O projeto delimitou-se a analisar o processo de trabalho de compostagem da Central de Saneamento Szachna Eliasz Cynamon, da Fundação Oswaldo Cruz (campus Manguinhos/RJ), no âmbito do Departamento de Gestão Ambiental da Coordenação Geral de Infraestrutura do Campus, que se insere no compromisso socioambiental da instituição de agir de forma sustentável (COGIC, 2019).

Para realização da Análise Ergonômica do Trabalho (AET), no âmbito da disciplina mencionada anteriormente, optou-se pela utilização do método EAMETA, uma ferramenta de apreciação ergonômica. A premissa da Ergonomia da Atividade é a da adaptação do trabalho ao homem, para isso busca evidenciar a maneira como o trabalho é realizado. $\mathrm{Na}$ análise do cotidiano da produção é que se revelam os modos operatórios e regulações, que ultrapassam os procedimentos previstos. A tarefa é a designação de um roteiro de trabalho; são as especificações com base nos objetivos concretos que sua execução deve proporcionar - o trabalho prescrito. A atividade é a ação em si da tarefa, e, a forma como que se desempenha a tarefa é o trabalho real, e entre a tarefa e a atividade há um ajuste, que leva a uma redefinição dos objetivos inicialmente fixados (ALVAREZ; TELLES, 2004).

O EAMETA baseia-se em cinco itens estruturantes da grande maioria dos ambientes de trabalho, possuindo caráter de grande generalidade. A sigla refere-se às primeiras letras das rubricas Espaço, Ambiente, Mobiliário, Equipamento, Tarefa e Atividade (BONFATTI; VIDAL; MAFRA, 2011). O método tem como objetivo a interação com os trabalhadores. Assim, a observação prévia dos trabalhadores em situação de trabalho foi seguida por entrevistas durante a fase de trabalho de campo da disciplina. $\mathrm{Na}$ ocasião, o setor contava com seis trabalhadores com idade entre 24 e 31 anos, um encarregado e um supervisor.

Inicialmente foram entrevistados dois trabalhadores para iniciarmos a aproximação. Nesse momento, solicitamos que pontuassem os itens do EAMETA. Com isso, calculou-se a média da pontuação dos trabalhadores e comparou-se com as pontuações dadas pelo analista, a fim de identificar (em amarelo - Tabela 1) as menores pontuações (condições de trabalho menos adequadas) e as principais discrepâncias na avaliação. 


\begin{tabular}{|l|c|c|}
\hline \multicolumn{3}{|c|}{ ESPACO } \\
\hline \multicolumn{1}{|c|}{ Item } & Trabalhador & Observador \\
\hline Circulação & 10 & 8 \\
\hline Area do Posto & 9 & 8 \\
\hline Leiaute & 10 & 10 \\
\hline Harmonia & 10 & 10 \\
\hline Sinalização & 9 & 4 \\
\hline
\end{tabular}

\begin{tabular}{|l|c|c|}
\hline \multicolumn{3}{|c|}{ AMBIENTE } \\
\hline \multicolumn{1}{|c|}{ Item } & Trabalhador & Observador \\
\hline Luz & 10 & 6 \\
\hline Ruido & 10 & 5 \\
\hline Temperatura & 4 & 4 \\
\hline Vibração & 10 & 10 \\
\hline Odores & 10 & 10 \\
\hline Poeiras & 5 & 5 \\
\hline Cores & 10 & 10 \\
\hline Ventilação & 10 & 7 \\
\hline Hurnanização & 10 & 10 \\
\hline Beleza & 10 & 10 \\
\hline
\end{tabular}

\begin{tabular}{|l|c|c|}
\hline \multicolumn{3}{|c|}{ MOBILIARIO } \\
\hline \multicolumn{1}{|c|}{ Item } & Trabalhador & Observador \\
\hline Cadeira & 10 & 4 \\
\hline Mesa & 10 & 5 \\
\hline Armários & 10 & 7 \\
\hline Lixeiras & 10 & 7 \\
\hline Cabides & 10 & 10 \\
\hline
\end{tabular}

\begin{tabular}{|c|c|c|}
\hline \multicolumn{3}{|c|}{ EQUIPAMENTO } \\
\hline Item & Trabalhador & Observador \\
\hline Ferram entas & 10 & 8 \\
\hline Maquinário & 9 & 8 \\
\hline
\end{tabular}

Tabela 1 - Itens do EAMETA avaliados pelos trabalhadores.

Durante as falas dos trabalhadores, percebemos dificuldades para compreensão das escalas e observamos que havia uma tendência a pontuarem com nota máxima os itens. Muitas condições de trabalho inadequadas eram consideradas suficientes para os trabalhadores, como a sinalização (nota média 9), cadeiras (nota média 10) e armários (nota média10). Na análise ergonômica, observou-se ausência de sinalização na sala de máquinas, as cadeiras estavam em mau estado de conservação e não possuíam adequação ergonômica e os armários estavam enferrujados.

As falas dos trabalhadores nas entrevistas individuais sinalizam também pouca preocupação ou sublimação dos riscos da atividade, assim como o movimento excessivo do corpo. A maioria das falas se refere a uma satisfação com o coletivo de trabalho, as afinidades entre os colegas e a autonomia para realização das tarefas de forma livre.

Para dar seguimento à análise deste processo retornou-se ao campo considerando a perspectiva ergológica, ocasião na qual foram entrevistados mais dois trabalhadores. Nessa ótica, entende-se que o real do trabalho dificilmente é acessível à primeira vista. Os trabalhadores sabem sobre seu trabalho, mas sua verbalização precisa ser estimulada para acessar as maneiras de fazer e os debates de normas. É o caráter enigmático da atividade (SCHWARTZ; DURRIVE, 2010). Analisar a atividade é confrontar-se com este enigma. Falar sobre o trabalho e analisar as práticas linguageiras passa a ser um passo fundamental para entender parte do enigma da atividade.

No âmbito das práticas linguageiras, os estudos ergológicos indicam três modalidades: a linguagem como trabalho (constitutivo da atividade), a linguagem no trabalho (constitutivo 
da situação de trabalho) e a linguagem sobre o trabalho (relativo à produção de saberes). Classificação que busca identificar os mecanismos de funcionamento da relação trabalholinguagem (entre o fazer e o dizer) e analisar a suas condições de produção (NOUROUDINE, 2002).

Há níveis de linguagem em que o protagonista do trabalho se situa - ora direcionando sua fala e gestos para os outros - ora estabelecendo um diálogo interno, orientando a si mesmo enquanto trabalha e - ora fazendo um mínimo dialógico, um diálogo reflexivo e silencioso que acontece na realização da atividade. Então, toda a complexidade encontrada no trabalho é também encontrada na linguagem em relação com o trabalho.

Nouroudine (2002) trata a linguagem como um dispositivo potente para revelar essa complexidade. Assim, pode-se concluir com o autor que os métodos de observação do trabalho podem acessar a linguagem já exteriorizada que se dá para o coletivo e para si. Mas somente com a colaboração dos protagonistas do trabalho, as entrevistas e os métodos de autoconfrontação podem permitir acessar os níveis mais profundos da linguagem.

$\mathrm{Na}$ perspectiva ergológica, valorizar a linguagem sobre o trabalho emitida pelos operadores, provoca o reconhecimento dos conhecimentos que comporta. É preciso cuidar para a linguagem científica e conceitual não ser inadequada e simplificadora em relação às experiências vividas por outros. É preciso construir um processo dialógico e dialético entre pesquisadores e trabalhadores para co-elaborarem uma linguagem sobre o trabalho (NOUROUDINE, 2002). É preciso compreender que "não se pode perceber e estudar o sujeito enquanto tal como se fosse uma coisa, visto que ele não pode permanecer sujeito se não tem voz; por conseguinte, seu conhecimento somente pode ser dialógico" (BAKHTIN apud NOUROUDINE, 2002, p. 29).

Assim, neste tipo de estudo é preciso utilizar métodos que permitam uma produção coletiva e que coloquem em prática o que a Ergologia chama de Dispositivo Dinâmico de Três Polos (DD3P). Tal dispositivo busca transformar positivamente o trabalho, ressaltando a interlocução entre os dois polos: de saberes relativos ao trabalho humano - os saberes formais, gerados por diversas disciplinas e campos de conhecimento, e os saberes advindos da experiência prática dos trabalhadores - o que exige um terceiro polo, o da postura éticoepistêmica, que promove o diálogo, a partir da simetria dos saberes, fazendo-os circular para emergir um saber compartilhado (SCHWARTZ; DURRIVE, 2010).

Após a análise do material das entrevistas realizadas com os quatro trabalhadores foi realizada uma devolutiva com todos os seis trabalhadores do processo de compostagem na perspectiva de diálogo e desenvolvimento de recursos para ação. Esta devolutiva aconteceu 
utilizando o dispositivo dos Encontros sobre o Trabalho (EST). Os EST são um espaço de circulação dialógica com foco na atividade de trabalho que envolve de forma comum seus participantes.

Esse espaço deve contemplar o debate sobre as normas antecedentes do trabalho (prescrições, regulamentações, condições de realização) e o que se caracteriza por renormatizações (mobilizações individuais e coletivas necessárias para a realização da atividade). Objetivou-se proporcionar aos trabalhadores um espaço de troca, criando uma situação favorável para que os protagonistas pudessem falar sobre sua atividade e através de uma postura dialógica criar novos pontos de vista sobre a ação (SCHWARTZ; DURRIVE, 2010).

Os resultados da análise ergonômica realizada, as fotos e vídeos dos profissionais em situação de trabalho e trechos de falas das entrevistas iniciais foram utilizados como elementos propulsores do debate de forma a estimular a atividade linguageira sobre o trabalho. A utilização desses recursos viabilizou uma espécie de confrontação para os trabalhadores, estimulando a discussão e a circulação dos saberes. A abordagem utilizada considerou a complexidade da dinâmica das trocas verbais e que o que é sentido pelos trabalhadores não pode ser restringido ao que é dito por eles (ROCHA; DEUSDARÁ, 2014).

\section{RESULTADOS}

A compostagem é um processo biológico que acelera a decomposição dos resíduos orgânicos transformando-os em composto. É uma forma de recuperar os nutrientes dos resíduos e levá-los de volta ao ciclo natural (COGIC, 2017). Na Fiocruz, a compostagem tem o objetivo de transformar o resíduo vegetal oriundo de poda, capina e varrição do campus e do resíduo orgânico oriundo da Creche e do restaurante da Escola Politécnica de Saúde Joaquim Venâncio em adubo para produção de mudas, manutenção dos jardins em projetos paisagísticos e para campanhas de sensibilização ambiental. Em 2019, a produção mensal do composto era de cerca de 20 toneladas. Abaixo a descrição do processo de compostagem: 


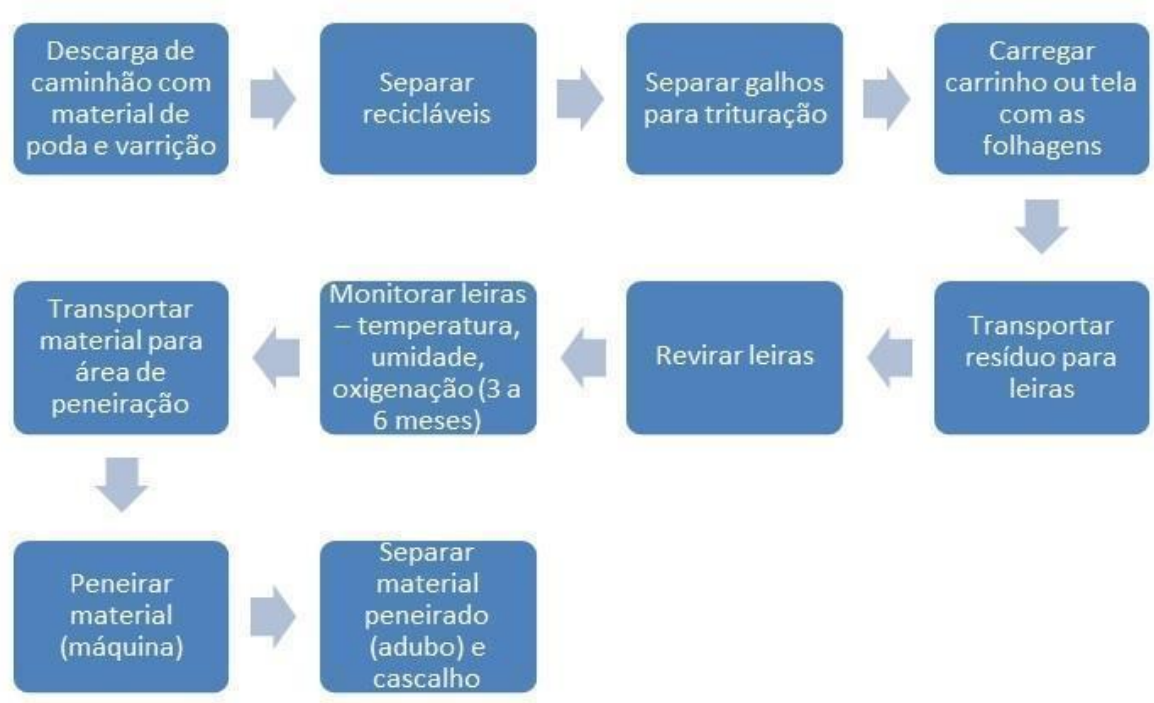

Figura 1: Fluxograma do processo de compostagem

O processo inicia com a descarga do resíduo vegetal (Figura 2) de caminhão ou trator na Central de Saneamento. Deste resíduo são separados os recicláveis e os galhos (encaminhados para trituração) (Figura 3). Em seguida, o carrinho ou tela (rede) é carregado com o resíduo, que é transportado (Figura 4) para as leiras (montinhos de diversas camadas de folhas, resíduo orgânico e picado/cascalho, que é o galho triturado - Figura 5).

Estas leiras são montadas, reviradas e monitoradas por 3 a 6 meses para verificar a temperatura, umidade e oxigenação para garantir a adequada decomposição do resíduo. Após esse tempo, o adubo é transportado para ser peneirado através de uma máquina alimentada pelo trabalhador (Figura 6). O adubo peneirado é separado (à esquerda - Figura 7) para ser utilizado e o cascalho residual (à direita - Figura 7) volta para a leira ou é utilizado em projetos paisagísticos.

Este é o processo principal da compostagem, mas existem vários outros subprocessos referentes ao tratamento de resíduo orgânico, à trituração, à peneiração, entre outros.

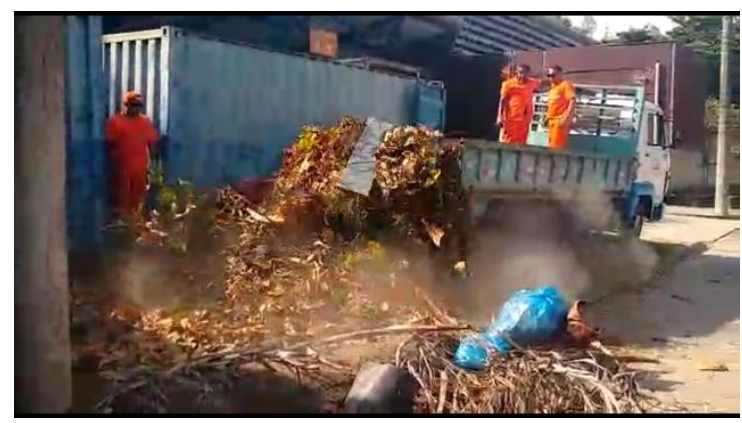

Figura 2 


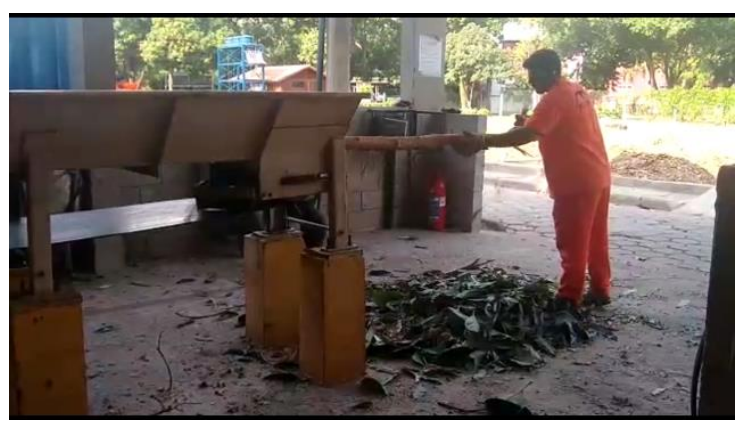

Figura 3

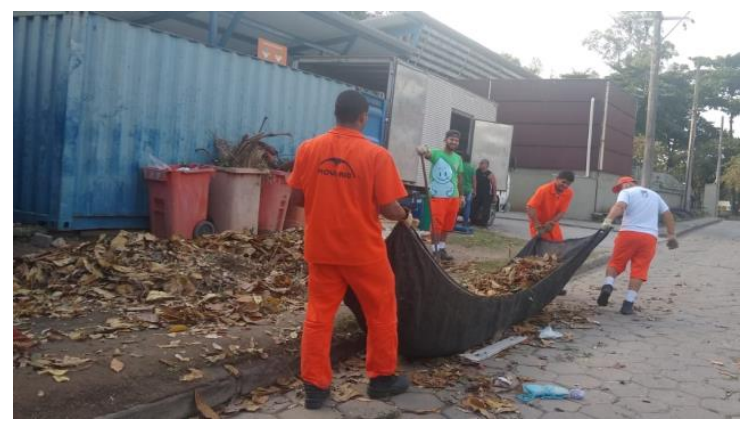

Figura 4

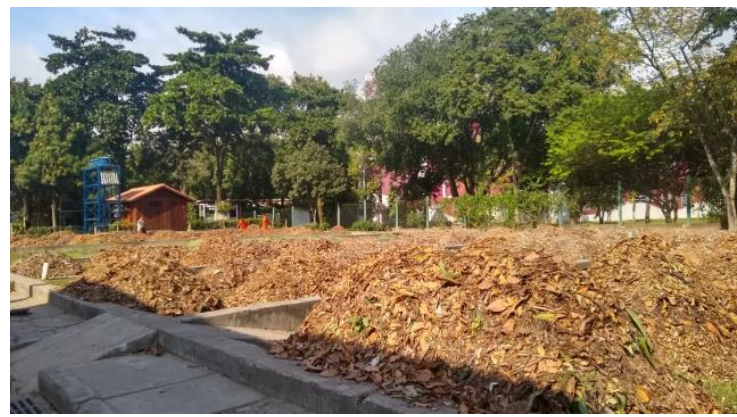

Figura 5

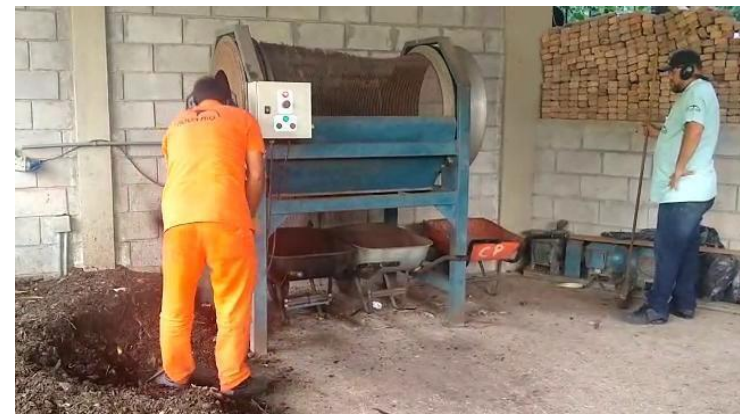

Figura 6

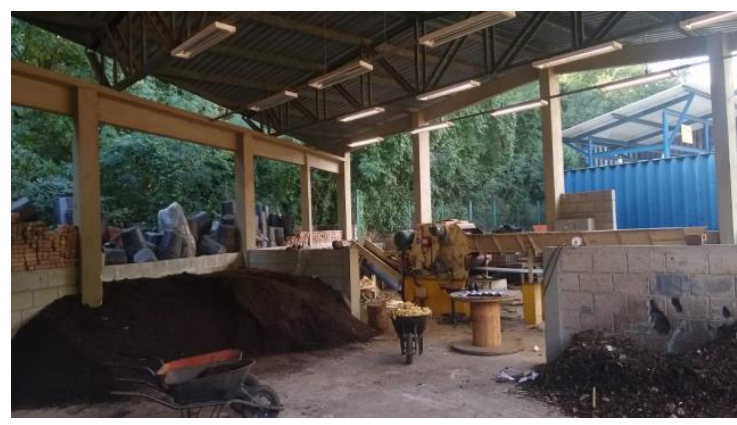

Figura 7 
Cabe mencionar que o espaço físico utilizado não fora construído para essa finalidade, não sendo totalmente adequado às especificidades do trabalho. Além disso, neste espaço coabitam outros processos do Departamento de Gestão Ambiental, como a coleta seletiva, o gerenciamento de resíduos perigosos e da estação de tratamento de esgoto.

As posturas para realização das tarefas exigem os membros superiores, rotação e flexão de tronco e o trabalho é realizado em pé. São atividades de repetição (alimentar a trituradora, peneirar, revirar a leira), atividades de força (levantar galhos, transportar carrinho de mão ou tela), atividades visuais (atenção ao lixo e aos insetos) e mesmo atividades sensoriais (verificar temperatura e umidade da leira). Os trabalhadores precisam utilizar ferramentas e equipamentos e fazer uso de EPIs. E o trabalho é realizado a céu aberto ou embaixo de telhas, deixando-os sujeitos a muito calor.

Assim, algumas sugestões ergonômicas foram levadas aos trabalhadores e superiores como: utilização de máscara para proteger da poeira, sinalizar melhor o local de trabalho, melhorar a iluminação do ambiente de maquinário, entre outras, para que pudessem analisar.

Foi possível identificar que muitas vezes o trabalhador não se dá conta da complexidade de seu trabalho. Ao ser questionado sobre as prescrições diárias, o trabalhador W disse "todo o dia a gente faz a mesma coisa. Não enjoa não". Considerando o real do trabalho, sujeito à variação temporal, tem dias com sol forte ou chuva, a demanda aumenta quando chega grande quantidade de material de poda, entre inúmeras outras situações que interferem na dinâmica de trabalho.

O trabalhador W disse "aqui pega fácil, foi fácil de pegar o trabalho", mas passados onze meses na atividade disse que "ainda está pegando a manha". Enquanto o trabalhador A, que trabalha no local há quatro anos, disse se referindo aos trabalhadores de outras áreas que eventualmente são direcionados para ajudar na compostagem: "eles não peneiram igual a gente, a gente já tem um jeito certo. A gente faz em trinta, quarenta minutos, outro leva uma hora e vinte, uma hora e meia". Então, será que o trabalho é tão fácil de "pegar"? Na verdade, percebe-se o quanto o trabalho prescrito passa por uma singularização por cada trabalhador em contato com o real da atividade.

Cabe destacar que quando o trabalhador A fala sobre como realiza a peneira, seu corpo desperta, ele simula os movimentos, como pega a pá. É possível observar todo o engajamento do corpo. É a inteligência desse corpo-si que se observa quando ele diz “o pessoal novo chega aqui e agacha demais, aí dá dor nas costas, eu não. Eu fico só (fazendo o movimento que ele realiza)". 
Com a experiência adquirida pelo coletivo, os trabalhadores, como protagonistas, criam diversas estratégias para realizar uma atividade desgastante buscando uma economia do corpo. Sobre a utilização da rede para carregar as folhas, o trabalhador W comentou: "a rede foi do nada: pô, vamos tentar levar na rede? e levamos. Ai fica dois na frente e um atrás, assim é mais rápido, carrinho é mais demorado". Essa renormatização contribui na compreensão das dificuldades para a realização do trabalho. Mudança favorecida porque o encarregado já havia realizado aquele trabalho e o entendia. $\mathrm{O}$ trabalho ser direcionado por alguém que conhece o trabalho real faz toda diferença.

O trabalhador L disse: "a decisão é do nosso encarregado" sobre quem faz o quê e como, mas nas entrevistas foi identificada certa autonomia na organização do trabalho. $\mathrm{O}$ trabalhador W disse sobre a divisão das tarefas: "a gente vai mudando na hora, agora é sua vez, agora eu, todo mundo se entende". O trabalhador $\mathrm{R}$ completa: “O encarregado pergunta: vocês vão querer carregar agora as folhas ou a terra? E nós: não! Vamos carregar a terra que é melhor que de manhã que não tá sol. Ele pergunta a melhor forma".

Durante a devolutiva, os trabalhadores foram incentivados a descrever como costumam explicar a sua atividade para amigos e familiares. $\mathrm{O}$ trabalhador $\mathrm{R}$ disse: "Tem muita gente que diz que eu não faço nada. Pô, eu trabalho à beça! Uma vez eu filmei o trabalho para mostrar se eu não trabalho não. Dia de sol, quente, a gente peneirando, carregando folha no sol quente. Isso me motiva mais ainda pra eles verem que eu trabalho de verdade". O trabalhador filmar e explicar a dureza do seu trabalho é a construção de uma linguagem sobre o trabalho que mostra a importância do reconhecimento social para a construção identitária do sujeito e do coletivo.

No que se refere à linguagem como trabalho, quando o trabalhador $\mathrm{R}$ explica como se monta a leira "Aí joga uma camada de folha, faz o quadrado, a base, depois joga o picado, depois a lavagem, o legume. Aí joga folha de novo", percebe-se que cada coletivo de trabalho tem um conjunto de códigos próprios.

O trabalhador W comentou que eles conversam bastante sobre futebol durante o trabalho, fazem brincadeiras, "zoação". Em um trabalho exaustivo, essa linguagem no trabalho ajuda a amenizar o desgaste físico inerente à atividade, a distrair e a fortalecer o coletivo e a solidariedade. O trabalhador W diz: “Aqui a gente é mais um grupo, entendeu? A gente vem junto, a gente sai junto. Aqui a gente é mais união, aquela amizade boa, não tem discussão, não tem briga, cada um faz o seu e vai levando. O corpo, ele não é uma máquina né? (...) pô o rapaz tá febril, tá passando mal. Pô, pode ficar aí. Aí quando ele vê que tá melhorando, ele vem, ajuda a gente. A gente não força ele a fazer trabalho pesado”. 
Ficou evidente o quanto o sentido do trabalho é importante. $\mathrm{O}$ trabalhador $\mathrm{R}$ considerou: "Se não tiver o adubo não tem plantação, então nós somos de fazer a terra, o adubo. É assim, assim, tem etapas. Aí é que vira o tremendo do adubo!”. Ele complementa: “Aqui a compostagem é o coração da Fiocruz. Porque a Fiocruz depende de terra pra plantar porque tem muitas árvores".

Os trabalhadores se surpreenderam com os resultados apresentados nos EST, afirmando que de fato achavam que o trabalho era pesado, mas simples. E conforme viam suas falas e fotos, traziam mais exemplos de renormatizạçoes, das microgestões e decisões cotidianas, das dificuldades para enfrentamento do trabalho real. Um borbulhar de significados, de verbalizações, uma verdadeira dinâmica mobilizadora do coletivo.

\section{CONSIDERAÇÕES FINAIS}

Com o presente estudo exploratório, observou-se a potência dos Encontros sobre o Trabalho para ampliar o olhar ergológico sobre a atividade, dando visibilidade às renormatizações praticadas como importantes estratégias para a diminuição da carga de trabalho para redução da fadiga, propiciando um uso de si por si.

Uma gerência praticada pela hierarquia caracterizada pelo baixo controle sobre a produção permite o exercício de maior autonomia desses trabalhadores. Não só em relação à gestão das pausas e horários de descanso, mas também em relação à decisão pelo modo de realização das tarefas, possibilitando o desenvolvimento de diferentes modos operatórios, através do uso da comunicação e cooperação. As trocas linguageiras no e sobre o trabalho fortalecem a produção do coletivo ampliando sua possibilidade de ação.

Vale ressaltar, ainda, que o caráter não lucrativo da atividade de compostagem realizada em uma instituição pública possibilita uma organização mais fluida do trabalho. Em uma empresa voltada para o lucro poderia haver maior pressão para o cumprimento de metas e maior controle, significando maior exploração dos corpos desses trabalhadores.

Ao longo da pesquisa foram encontradas limitações como dificuldade no acesso ao campo e poucas oportunidades de contato com os trabalhadores, tendo em vista que para isso era necessário interromper a atividade por se tratar de uma zona com riscos ocupacionais. Ter mais tempo para observação da atividade e aproximação com os trabalhadores também teria contribuído para uma análise mais profunda.

Considerando que os trabalhadores nas entrevistas e na devolutiva citaram bastante o processo de varrição em comparação a sua atividade, pode-se sugerir uma análise deste outro processo de trabalho para entender melhor essas referências. Além disso, como nesta 
área de trabalho funcionam outros processos, como reciclagem, manejo de resíduos perigosos, entre outros, sugere-se conhecer as interseções entre a compostagem e as demais para identificar como essa relação afeta o trabalho. Não só por circularem no mesmo espaço, com também por compartilharem o vestiário, o refeitório e por vezes até equipamentos. Além do fato de se encontrarem sob mesmo vínculo empregatício.

Bem como, pode-se pensar na produção de novos olhares visando compreender a atividade de outros trabalhadores que exerçam atividade que assim como os da compostagem exijam bastante esforço físico. Pensar também em como muitas vezes a invisibilidade dessas atividades afetam a atividade e o trabalhador. Outras possibilidades de campo poderiam ser encontradas nos processos como os de limpeza, portaria, cozinha e segurança.

\section{REFERÊNCIAS}

ALVAREZ, D.; TELLES, A. L. Interfaces ergonomia-ergologia: uma discussão sobre trabalho prescrito e normas antecedentes. In: FIGUEIREDO et al. (Orgs.) Labirintos do trabalho: interrogações e olhares sobre o trabalho vivo. Rio de Janeiro: DP\&A, 2004. p. 63-90.

ANTUNES, Ricardo. Adeus ao trabalho? Ensaio sobre as Metamorfoses e a Centralidade do Mundo do Trabalho. 7 ed. São Paulo: Editora Cortez, 2009.

AZEREDO SILVA, J. T.; MUNIZ, H. P. Atividade de trabalho humana: características e desafios para sua compreensão. MNEMOSINE (RIO DE JANEIRO) v. 13, p. 40-58, 2017.

BONFATTI, R. J.; MAFRA, J. R.; VIDAL, M. C. EAMETA: um método para análise ergonômica. Rio de Janeiro, 2011. 16p. Apostila do Curso de Especialização Superior em Ergonomia - COPPE/UFRJ.

BRITO, Jussara. Saúde - uma relação com o meio e os modos de vida. Laboreal, v.13, n.1, p. 100-103, 2017.

CANGUILHEM, Georges. O Normal e o Patológico. 6a ed. Rio de Janeiro: Forense Universitária, 2009.

CAPONI, Sandra. Georges Canguilhem y el estatuto epistemológico del concepto de salud. História, Ciências, Saúde, v. IV, n. 2, p.287-307, 1997.

COGIC/FIOCRUZ. Coordenação Geral de Infraestrutura do Campus da Fundação Oswaldo Cruz. Os benefícios da compostagem. Rio de Janeiro. 27/09/2017. Disponível em <http://www.cogic.fiocruz.br/2017/09/os-beneficios-da-compostagem> Acesso em 10/07/2019.

COGIC/FIOCRUZ. Coordenação Geral de Infraestrutura do Campus da Fundação Oswaldo Cruz. Missão, Visão e Valores. Rio de Janeiro. Disponível em $<$ http://www.cogic.fiocruz.br/pagina-exemplo/missao-visao-e-valores $>$ Acesso em 10/07/2019. 
DEJOURS, C. Por um novo conceito de saúde. Revista Brasileira de Saúde Ocupacional, São Paulo, v. 14, n. 54, p. 7-11, abr./jun. 1986.

DURRIVE, Louis. A atividade humana, simultaneamente intelectual e vital: esclarecimentos complementares de Pierre Pastré e Yves Schwartz. Trab. educ. saúde (Online), Rio de Janeiro,v. 9, supl. 1, p. 47-67, 2011. Disponível em: http://dx.doi.org/10.1590/S1981-77462011000400003. Acesso em: 02 set. 2019.

FERREIRA, Mário César. Atividade, categoria central na conceituação de trabalho em ergonomia. Alethéia, v. 1, n. 11, p. 71-82, 2000.

NOUROUDINE, A. A linguagem: dispositivo revelador da complexidade do trabalho. In: SOUZA-E-SILVA, M. C.; FAÏTA, D. (Org.). Linguagem e trabalho: construção de objetos de análise no Brasil e na França. Tradução Ines Polegatto e Décio Rocha. São Paulo: Cortez, 2002.

OSORIO DA SILVA, C; RAMMINGER, T. O trabalho como operador de saúde. Ciência \& Saúde Coletiva, 19(12), 4751-4758, 2014.

RIFKIN, J. O fim dos empregos. São Paulo: Makron Books do Brasil, 1995.

ROCHA, D.; DEUSDARÁ, B. Argumentos para uma abordagem discursiva das práticas de linguagem no trabalho. Letras de Hoje, Porto Alegre, v. 49, n. 3, p. 297-305, jul.-set. 2014.

SCHWARTZ, Y. Qual sujeito para qual experiência? Revista Tempus Actas de Saúde Coletiva - O Trabalho em Saúde, Brasília, v. 5, n. 1, p. 55-67, 2011. Disponível em: $<$ http://www.tempusactas.unb.br/index.php/tempus/article/view/916/927>. Acesso em: 12 de julho de 2019.

SCHWARTZ, Y. \& DURRIVE, L. (Orgs). Trabalho e ergologia: conversas sobre a atividade humana. $2^{\mathrm{a}}$ edição, Niterói: EdUFF, 2010. 318p.

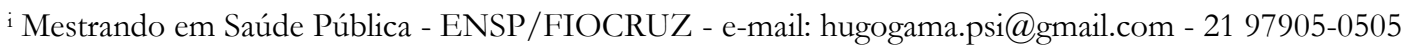

ii Mestranda em Saúde Pública - ENSP/FIOCRUZ - e-mail: samara.leal.psi@gmail.com - 21 98828-5227

iii Doutoranda em Saúde Pública - ENSP/FIOCRUZ - e-mail: talita.coelho@fiocruz.br - 21 97659-8778

iv Professora Orientadora - Doutora em Saúde Pública - ENSP/FIOCRUZ - e-mail: simone@ensp.fiocruz.br - 21 98102-3203

ENSP - ESCOLA NACIONAL DE SAÚDE PÚBLICA SERGIO AROUCA

Rua Leopoldo Bulhões, 1480 - Manguinhos, Rio de Janeiro. CEP: 21041-210 - Tel: (21) 2598-2525
} 